\title{
STUDY OF PREVALENCE OF G6PD DEFICIENCY IN RBC'S OF LIVE NEWBORNS BORN IN A TERTIARY CARE HOSPITAL
}

\author{
G. G. Joag1, Surbhi Garg²
}

${ }_{1}^{1}$ Associate Professor, Department of Paediatrics, KIMS, Karad, Maharashtra, India.

${ }^{2}$ Resident, Department of Paediatrics, KIMS, Karad, Maharashtra, India.

\begin{abstract}
BACKGROUND
G6PD deficiency is X-linked recessive disorder which affects more than 400 million people worldwide, representing an overall $4.9 \%$ global prevalence. Though the exact incidence in India is not known, various studies have reported an incidence ranging 2$27 \%$ in different communities in India. The present study was conducted to determine the prevalence of G6PD deficiency among the cases admitted in tertiary healthcare institute.
\end{abstract}

ABSTRACT

\section{METHODS}

This study was a prospective cross-sectional study conducted among 350 consecutively born live newborns in maternity wards and NICU of Krishna Institute of Medical Sciences, Karad, Maharashtra, from October 2016-October 2017.

\section{RESULTS}

In the present study, we assessed the family history of G6PD/ haemolytic disease or parents migrated from G6PD prevalent area. We observed that no newborn had positive family history of G6PD/haemolytic disease and no parents had migrated from G6PD prevalent area.

\section{CONCLUSIONS}

Early detection and prevention are the key for the successful management and control of G6PD deficiency. If the clinical and haematological findings raise the suspicion of glucose 6 phosphate dehydrogenase deficiency, the disorder should be confirmed by quantitative spectrophotometric measurement of red blood cell enzyme activity.

HOW TO CITE THIS ARTICLE: Joag GG, Garg S. Study of prevalence of G6PD deficiency in RBC's of live newborns born in a tertiary care hospital. J. Evolution Med. Dent. Sci. 2019;8(18):1451-1454, DOI: 10.14260/jemds/2019/323

\section{BACKGROUND}

Glucose-6-phosphate dehydrogenase deficiency is a hereditary metabolic defect characterized by an increased tendency of the red blood cells to break and release their haemoglobin (Haemolysis), especially after the intake of certain drugs. As the name indicates, this condition is caused, by the markedly reduced activity in the red blood cells of a glucose-6-phosphate dehydrogenase (An organic catalyst, or enzyme). This low enzyme activity is associated with a decrease in the formation of certain substances that normally help to prevent the oxidative destruction of the red blood cell membrane. G6PD deficiency is a known X-linked recessive disease which globally affects more than 400 million population (4.9\%). ${ }^{1}$ This disorder occurs more commonly among males as compared to females.

As we all know, India is in the stage of epidemiological transition. Communicable diseases and sepsis is gradually being replaced by non-communicable diseases, congenital malformations and genetic disorders which were considered as the major causes mortality among children in India.

'Financial or Other Competing Interest': None.

Submission 07-02-2019, Peer Review 18-04-2019,

Acceptance 24-04-2019, Published 06-05-2019.

Corresponding Author:

Dr. Surbhi Garg,

Department of Paediatrics,

Krishna Institute of Medical Sciences,

Karad, Maharashtra, India.

E-mail: researchexpert3@gmail.com

DOI: $10.14260 /$ jemds $/ 2019 / 323$
Currently, congenital malformations and genetic disorders constitute the fourth commonest cause (i.e.9.2\%) of total neonatal mortality in urban areas in India. It is estimated that at least 390, 000 children suffering from G6PD deficiency disorder out of almost 24 million children born annually in India are born in the country every year.

In India, G6PD deficiency was first reported in 1963 by Baxi et al., and the prevalence rate varied from 0 to $27 \%$ in different caste, ethnic, and linguistic groups. The frequency is higher among the tribals than the caste populations. One of the most important reasons for this can be that the consanguineous marriages are still fairly common in many parts of India. ${ }^{2}$

\section{Aims and Objectives}

The present study was conducted to assess prevalence of G6PD deficiency in RBC's of newborns born at tertiary care hospital, and hence to study risk factors associated with G6PD deficiency.

\section{METHODS}

This study was a prospective cross-sectional study conducted among 350 consecutively born live newborns in maternity wards and NICU of Krishna Institute of medical sciences and hospital and research centre, Karad, Maharashtra during October 2016-October 2017.

After obtaining an informed consent taken from the parents of the neonate after explaining in detail about the procedure of the study in their vernacular language. The study was approved by the institutional ethical committee of KIMSDU, Karad. 
Babies who were not born at this tertiary care hospital, Babies who were stillborn or expired, who were born preterm/IUGR/SGA/congenital anomalies/sick babies or babies who received blood transfusion or undergone exchange transfusion and babies whose parents had not given consent were excluded from the given study

Details of maternal parameters like name, age, hospital details, type of delivery, any risk factors, past obstetric history, any medical and surgical illness were recorded in proforma. Details of neonate like date of delivery, sex, birth weight \& history of previous babies having haemolysis or blood transfusion and examination details were recorded. The data was entered and represented using tables and charts for descriptive statistics.

\section{RESULTS}

In the present study, the majority of the newborns belonged to the age group of $0-10$ hours $(36.80 \%)$, followed by in 11 20 hours $(21.80 \%)$. The mean age among newborns was 2.86 \pm 5.83 hours. (Table 1) Out of 350 cases females were 181 $(51.71 \%)$ and males $(48.29 \%)$ and female to male ratio was 1.07:1. The majority of newborns had birth weight 2500 3000 grams (52.86\%) followed by $>3000$ grams $(28 \%)$ and $<2500$ grams (19.14\%). (Table 2)

In the present study, the prevalence of G6PD deficiency among newborns who were tested was $0 \%$. It was observed that the majority of newborns were Hindu by religion (67.14\%) followed by Muslims (22.86\%), 6\% newborns were Buddhist and $4 \%$ of other religion.

The majority of newborns were born out of NonConsanguineous marriage $(85.43 \%)$ followed by marriages of 3rd degree Consanguinity (12.28\%). The 1st degree Consanguinity was present among $1(0.29 \%)$ patient. It was observed that the majority of newborns were Hindu by religion (67.14\%) with maximum number of third degree consanguinity (16.59\%) and second degree consanguinity (2.97\%) followed by Muslims (22.86\%) in whom third degree consanguinity was around (5\%), 6\% newborns were from Buddhist and 4\% from other religion. (Table 3) Majority of mother of newborns were in 2-3 gravidity (51.43\%) followed by primi gravid mothers (42.86\%).

(Figure 1)

In the present study, we assessed the family history of G6PD/haemolytic disease or parents migrated from G6PD prevalent area. We observed that no newborn had positive family history of G6PD/haemolytic disease and no parents had migrated from G6PD prevalent area.

It was observed that the majority of newborns had normal haemoglobin [275 (78.57\%)] while 63 newborns (18\%) had anaemia. ( $\mathrm{Hb}<17.1 \mathrm{gm} \%)$ while 12 newborns had polycythaemia $(\mathrm{Hb}>20.9)$. As per Nelson textbook defining normal range of haemoglobin in newborn of 1-2 days of life as $19+/-1.9 \mathrm{gm} / \mathrm{dl}$.(Figure 2)

In the present study we assessed the history of nonoxidant and oxidant drug given or taken during pregnancy that can trigger haemolysis in G6PD deficient newborns. It was observed that the majority of mothers 341 (97.43\%) had no history of oxidant drug intake while other $9(2.57 \%)$ mothers had positive history of Oxidant drug intake. (Figure 3).

\begin{tabular}{|c|c|c|}
\hline Age Group (Hours) & No. of New Born & Percentage \\
\hline $0-10$ & 337 & 96.29 \\
\hline $11-20$ & 06 & 01.71 \\
\hline $21-30$ & 02 & 00.57 \\
\hline $31-40$ & 01 & 00.29 \\
\hline$>40$ & 04 & 01.14 \\
\hline Total & $\mathbf{3 5 0}$ & $\mathbf{1 0 0}$ \\
\hline \multicolumn{2}{|c|}{ Table 1. Distribution of Newborns According to Age } \\
\hline
\end{tabular}

\begin{tabular}{|c|c|c|}
\hline Birth Weight (Grams) & No. of New Born & Percentage \\
\hline$<2500$ & 67 & 19.14 \\
\hline $2500-3000$ & 185 & 52.86 \\
\hline$>3000$ & 98 & 28.00 \\
\hline Total & $\mathbf{3 5 0}$ & $\mathbf{1 0 0}$ \\
\hline \multicolumn{2}{|c|}{ Table 2. Distribution of Newborns According to Birth } \\
Weight \\
\hline
\end{tabular}

\begin{tabular}{|c|c|c|c|c|c|}
\hline \multirow{2}{*}{ Religion } & \multicolumn{4}{|c|}{ Consanguinity } & \multirow{2}{*}{ Total } \\
\hline & No & 10 & 2 o & 3o & \\
\hline Hindu & 188 & 01 & 07 & 39 & 235 \\
\hline Muslim & 76 & 00 & 00 & 04 & 80 \\
\hline Buddhist & 21 & 00 & 00 & 00 & 21 \\
\hline Others & 14 & 00 & 00 & 00 & 14 \\
\hline Total & 299 & 01 & 07 & 43 & 350 \\
\hline \multicolumn{6}{|c|}{$\begin{array}{l}\text { Table 3. Newborns Distribution According to Religion anc } \\
\text { Consanguinity }\end{array}$} \\
\hline
\end{tabular}
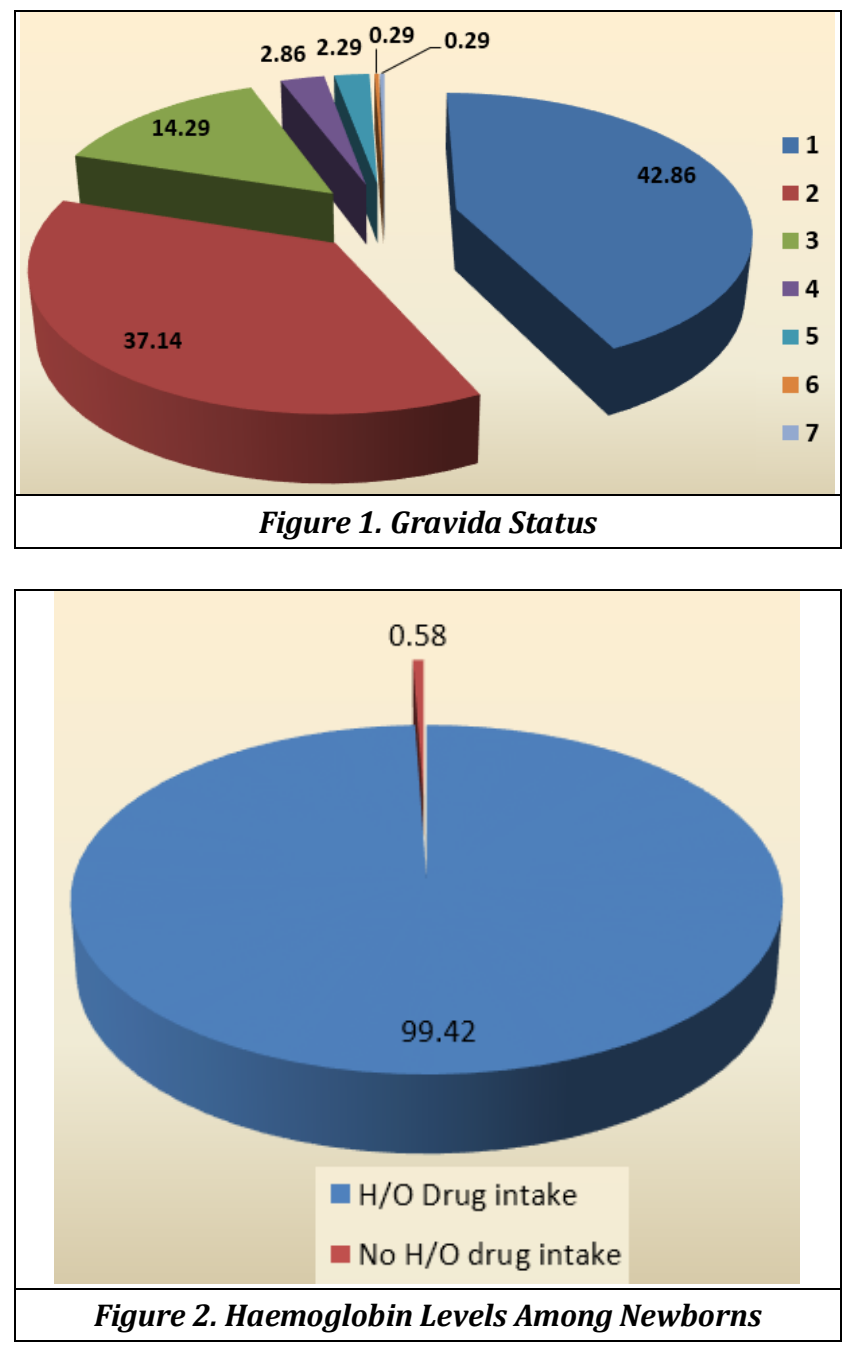


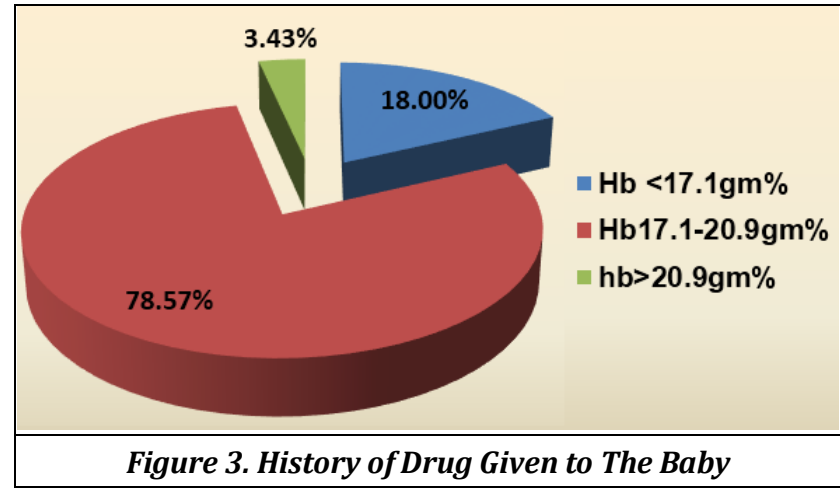

\begin{tabular}{|c|c|c|}
\hline History of Drug Intake & No. of Newborn & $\%$ \\
\hline Oxidant drug (Vit. K) & 341 & 97.43 \\
\hline $\begin{array}{c}\text { Oxidant drug (Vit. K) \& } \\
\text { Non oxidant drug (Inj Ampicillin, } \\
\text { Inj. Gentamycin) }\end{array}$ & 07 & 02.00 \\
\hline No drugs & 02 & 00.57 \\
\hline Total & 350 & 100 \\
\hline
\end{tabular}

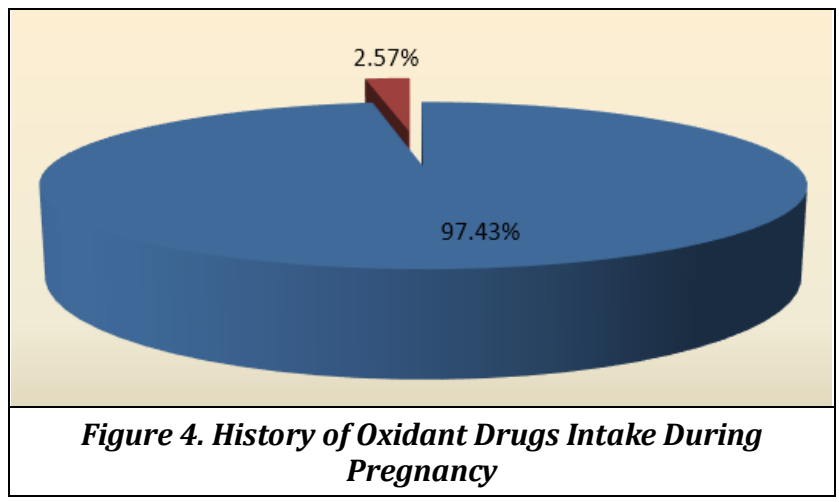

\section{DISCUSSION}

The present study was a prospective cross-sectional study undertaken to study the prevalence of G6PD deficiency in RBCS of live newborns born at tertiary care hospital. In the present study, age distribution among newborns showed that maximum numbers of newborns were in the age group of 0 10 hours $(96.29 \%)$, followed by in $11-20$ hours $(1.71 \%)$. With mean age among newborns was $2.86 \pm 5.83$ hours. Out of 350 newborns females were $181(51.71 \%)$ to males (48.29\%) and female to male ratio was 1.07:1.

Julien Didier Adedemy et $\mathrm{al}^{3}$ studied the prevalence of Glucose 6 Phosphate Dehydrogenase deficiency among infants and children of Parakou, Benin. Out of 510 infants and children were selected more than half were boys $(52.5 \%)$. Sudeb Mukherjee ${ }^{4}$ studied prevalence of Glucose 6 Phosphate Dehydrogenase deficiency in Eastern India, observed out of 250 newborns $74.4 \%$ were males while $25.6 \%$ were females.

It was observed that the majority of newborns had birth weight between 2500-3000 grams (52.86\%) followed by $>3000$ grams (28\%) and <2500 grams (19.14\%). The majority of newborns were Hindu by religion (67.14\%) followed by Muslims (22.86\%), Buddhist (6\%) and other religion (4\%). It was observed that the majority of newborns were of 1 st gravidity (42.86\%) followed by 2nd gravida (37.14\%)
Julien Didier Adedemy et $\mathrm{al}^{3}$ studied the prevalence of glucose 6 phosphate dehydrogenase deficiency among 510 infants and children included in the study, 104 were born from consanguineous parents (20.4\%). Among them, 68 were second degree relatives $(65.4 \%)$ and 36 were first to second degree (34.6\%). In the present study the prevalence of G6PD deficiency among newborns was $0 \%$. Malay B. Mukherjee et al ${ }^{5}$ studied glucose-6-phosphate dehydrogenase (G6PD) deficiency among tribal populations of India and observed that the prevalence varied from 1.4 to 31.4 per cent in western India comprising of Rajasthan, Gujarat, Dadra \& Nagar Haveli and Maharashtra.

Chandresh kumar Bavchandbhai Paneliyaet al $^{6}$ studied the incidence of G6PD deficiency amongst the ethnic groups from January 2013 to January 2014 in cord blood of all babies born at Nazareth Hospital, Meghalaya; during the study period, G6PD deficiency was seen in 43 out of 2400 newborns (1.8\%). G6PD deficiency was $1.9 \%$ in Assamese newborns and $4 \%$ amongst Bihari newborns.

The distribution of newborns according to Consanguinity showed that the majority of newborns were born out of NonConsanguineous marriage $(85.43 \%)$ followed by $3^{\text {rd }}$ degree Consanguinity $(12.28 \%)$. The $1^{\text {st }}$ degree Consanguinity was present among $1(0.29 \%)$ patient. It was observed that the majority of newborns were Hindu by religion (67.14\%) with maximum number of third degree consanguinity (16.59\%) and second degree consanguinity (2.97\%) followed by Muslims (22.86\%) in whom third degree consanguinity among muslim population is around (5\%), 6\% newborns were from Buddhist and $4 \%$ from other religion.

Julien Didier Adedemy et $\mathrm{al}^{3}$ studied the prevalence of glucose 6 phosphate dehydrogenase deficiency among 510 infants and children included in the study, 104 were born from consanguineous parents $(20.4 \%)$.

This topic was taken for study in view of starting screening of newborns for G6PD deficiency; so as to prevent haemolysis and recurrent haemolytic anaemia in these children. We wanted to see necessity of such screening program in our part of India. To educate parents so that they can take proper care and necessary precautions.

The routine screening of children for G6PD deficiency is recommended to allow evidence-based management of these children and to ensure the avoidance of food, drugs, and infective agents that have potential to predispose these children to oxidative stress. The cost of introducing the screening program can be justified by saving the life and the complications in these children's future life.

Pregnant and nursing women, who are heterozygous for G6PD deficiency should avoid drugs with oxidant potential, because some of these drugs gain access to the fetal circulation and to breast milk.

The global prevalence of G6PD deficiency is reported 5 to $25 \%$; in Asia the prevalence of G6PD deficiency is 31\%; In India prevalence for G6PD deficiency varies from 0 to $10 \%$ area to area; In Maharashtra region incidence is reported between 0 to $13 \%$.

In a large study among tribal population in India among Rajasthan, Gujarat, Dadra \& Nagar Haveli and Maharashtra, total 22 tribal groups were studied to find out the prevalence of G6PD deficiency. Their study reports the prevalence varied from 1.4 to $31.4 \% .7,8$ 


\section{Prevalence of G6PD Deficiency}

In the present study the prevalence of G6PD deficiency among newborns was $0 \%$. The distribution of newborns according to positive family history of G6PD/haemolytic disease showed that no newborn had positive family history of G6PD/haemolytic disease.

Searching for family history is important because G6PD deficiency is an X-linked recessive disorder, it is more common in males, while females can have a mutation in both copies of the G6PD gene, or can have only one mutation. Females with one mutation have lower G6PD activity than the normal due to skewed lyonization.

It was observed that no parents or close relatives had $\mathrm{H} / \mathrm{O}$ episodic or repeated blood transfusion for anaemia or any other haemolytic diseases, intra vascular haemolysis, acute renal shutdown, jaundice, black coloured urine or haemoglobinuria and no parents have migrated from G6PD prevalent area.

In this study, we observed that the majority of mothers $341(97.43 \%)$ had no history of oxidant drug intake while other $9(2.57 \%)$ mothers had positive history of oxidant drug intake. Oxidant drug given or taken during pregnancy can trigger haemolysis in G6PD deficient fetus and newborns.

The distribution of newborns according to haemoglobin levels showed that the majority of newborns had normal haemoglobin 275 (78.57\%) while 63 newborns (18\%) had anaemia $(\mathrm{Hb}<17.1$ gm\%) while 12 newborns had polycythaemia $(\mathrm{Hb}>20.9 \mathrm{gm} \%)$. In present study it was observed that the out of 350 newborns majority of newborns had no hyperbilirubinemia (99.14\%) while 3 (0.86\%) newborns had presence of hyperbilirubinemia. All hyperbilirubinaemic newborns were treated with phototherapy while 1 (33.33\%) newborn required exchanges transfusion in addition to phototherapy.

In a study by Manik Mondal et al in Sammilani Medical College during the period from November 2010 to December 2010, out of 176 newborns, the 24 neonates with G6PD deficiency required phototherapy for duration of more than 24 hours. Two babies (8.33\%) required phototherapy for a period of 24 to 48 hours. Eight (33.33\%) needed phototherapy for 48 to $72 \mathrm{hrs}$. Ten (41.66\%) required phototherapy for a period of 72 to $96 \mathrm{hrs}^{9}$

\section{CONCLUSIONS}

Early detection and prevention are the key for the successful management and control of G6PD deficiency. If the clinical and haematological findings raise the suspicion of glucose 6 phosphate dehydrogenase deficiency, the disorder should be confirmed by quantitative spectrophotometric measurement of red blood cell enzyme activity.

G6PD deficiency is one of the major causes of neonatal jaundice within 24 hours of life in newborns. Hence, neonatal screening for G6PD deficiency could be an alternative to the haemolytic crisis prevention strategy in order to optimize affected young child care and prevention of crisis occurrence by avoiding contraindicated foods and drugs.

\section{REFERENCES}

[1] World Health Organization. Standardization of procedures for the study of glucose-6-phosphate dehydrogenase. Report of a WHO Scientific Group. World Health Organ Tech Rep Ser 1967;366:1-53.

[2] World Health Organization. Worldwide Prevalence of G6PD Deficiency according to the World Health Organization. 2003.

[3] Adedemy JD, Gomina M, Agossou J, et al. Prevalence of glucose 6 phosphate dehydrogenase deficiency among infants and children of Parakou, Benin. Curr Pediatr Res 2015;19(1\&2):58-65.

[4] Sudeb M. Prevalence of glucose 6 phosphate dehydrogenase deficiency in Eastern India, a study from a tertiary care hospital. JOJ Pub Health 2017;2(5):555599.

[5] Mukherjee MB, Colah RB, Martin S, et al. Glucose-6phosphate dehydrogenase (G6PD) deficiency among tribal populations of India - Country scenario. Indian J Med Res 2015;141(5):516-20.

[6] Paneliya CB, Lurshay RM, Deb S, et al. Incidence of G6PD deficiency and its association with neonatal jaundice in babies born at a tertiary care hospital in Meghalaya. International Journal of Scientific Research 2016;5(12):70-3.

[7] Rao VR, Gorakshakar AC. Sickle cell hemoglobin, $\beta$ Thalassemia and G6PD deficiency in tribes of Maharashtra, India. Gene Geogr 1990;4(3):131-4.

[8] Bhasin MK. Genetics of castes and tribes of India: glucose-6-phosphate dehydrogenase deficiency and abnormal hemoglobins ( $\mathrm{Hb} \mathrm{S}$ and $\mathrm{Hb} \mathrm{E}$ ). Int J Hum Genet 2006;6(1):49-72.

[9] Mondal M, Datta AK, Mandal S, et al. Study of Glucose 6-Phosphate dehydrogenase deficiency in neonatal Jaundice. IOSR Journal of Pharmacy and Biological Sciences 2012;1(5):30-6. 